\title{
Modelling and cost evaluation of electro-coagulation processes for the removal of anions from water
}

\author{
Engracia Lacasa ${ }^{1}$, Pablo Cañizares ${ }^{1}$, Cristina Sáez ${ }^{1}$, Fabiola Martínez ${ }^{2 *}$, Manuel A. \\ Rodrigo ${ }^{1}$ \\ ${ }^{1}$ Department of Chemical Engineering. Faculty of Chemical Sciences. University of Castilla-la \\ Mancha. Avda. Camilo José Cela, 12. 13071 Ciudad Real. Spain. \\ ${ }^{2}$ Department of Chemical Engineering. Faculty of Environmental Sciences and Biochemistry. \\ University of Castilla-la Mancha. Avda. Carlos III, s/n, 45071 Toledo, Spain
}

\begin{abstract}
A mathematical model previously proposed by our group has been modified for its application in the modelling of arsenates, nitrates and phosphates electro-coagulation with iron and aluminium. It classifies the coagulant and pollutant species attending to their reactivity in the electro-coagulation process on the basis of the experimental behaviour of the system. The enmeshment of anionic pollutants in a growing coagulant precipitate and their direct precipitation are the mechanisms considered. A good reproducibility of the experimental data is obtained (with $r^{2}$ above 0.9) with a small number of parameters. The model has been used to predict the amount of coagulant dose required under given conditions for the removal of the anionic pollutants, which allowed obtaining the costs of the electro-coagulation corresponding to the raw material, iron or aluminium sheets, and the energy costs for their electro-dissolution. Results showed that iron electro-coagulation is cheaper than aluminium electro-coagulation, and that the current density does not have an important influence on the costs within the range studied $(0.2$ to $4.0 \mathrm{~mA} \mathrm{~cm}$ ). Attending to the results, arsenate and phosphate removal by electro-coagulation seem to be attractive from the economic point of view.
\end{abstract}

\section{Keywords}

Electro-coagulation, nitrates, phosphates, arsenates, modeling, economic evaluation

* To whom correspondence should be addressed. Tel. +34 902204100

Fax: +34925268840

E-mail: fabiola.martinez@uclm.es 


\section{Introduction}

Electro-coagulation has been a promising technology aiming to destabilize and remove finely particles from waters and wastewaters since the beginning of the $20^{\text {th }}$ century. Presently, it is considered as a prospectively competitive technology for the removal of pollutants from supply water [1], urban wastewater [2], and also for the treatment of industrial effluents [3] such as those generated in agro-alimentary [4], metalworking [5] and textile industries [6,7]. The proper design of the electrochemical cell, the application to proper issues, the easiness in the automation [8,9] and the low energy requirements (which even allows using of solar power, wind mills and fuel cells [10]) have become in the greater challenges and, at the same time, in important advantages for the use of electrochemical coagulation plants. Nevertheless, to make electrochemical coagulation not only competitive with the conventional coagulation technology in-use today but also the reference technology in some applications, more effort has to be done in the next years, and a better understanding of the processes involved must be achieved. In addition, accurate estimations of cost could help to discern when this electrochemical technology can be an advantage in the remediation of a particular environmental issue.

In this context, the development of mathematical models, that are consistent with the processes occurring in a physical system, can be a relevant approach because such models can help to understand what is happening in the treatment process. In turn, a more detailed knowledge of the physical system can be obtained, and tools for a proper design of the processes, or for the analysis of possible operating situations, can be attained. For this reason, in recent years several models have been developed to describe the electro-coagulation processes for the treatment of wastewaters [11-15], although a model able to completely represent every process involved in this type of treatment is still a long way off. These models correspond to different approaches to describe the physical processes occurring within the electrochemical reactors.

Actual processes can be very complex, and normally a mathematical model is only going to capture the more significant features of them and not to try to obtain the exact equivalent of a physical system. Thus, in chemical engineering it is usual to try to use models in which process variables do not depend on the position but only on the time. These models are called lumped-parameter models, and in non-steady state conditions 
they take the form of a set of ordinary differential equations, in which the time is the only independent parameter. In addition, in any chemical or electrochemical process, the application of the conservation principles provides the outline for building phenomenological mathematical models. To complement these equations, the use of constitutive equations based on physical, chemical or electrochemical laws is required to model the primary mechanisms by which changes within the process are assumed to occur (rates of the processes, calculation of properties, etc.).

The mathematical model proposed in this work, is based on the previous phenomenological model developed by the group of Prof. Lapicque [11,12] to calculate the efficiency of an electro-coagulation process in the removal of suspended particles from wastewater using sacrificial aluminium anodes. In this previous model, it is assumed that the limiting step in the electro-coagulation process is the reaction between the pollutant species and the coagulants used. As this reaction is assumed to be fast, the model developed by this group considers pseudo-equilibrium constants for the interaction between coagulants and pollutants. Different reaction stages have been used to describe this interaction for different processes. For example, to predict the discontinuous electro-coagulation process in the treatment of oil suspensions [11] it was proposed that the adsorption of organic matter onto aluminium hydroxide precipitates is the limiting mechanism. Moreover, for the treatment of several liquid wastes with suspended pollutants (in which the pollutant concentration was included in the COD (chemical oxygen demand) parameter) an equilibrium reaction between the aluminium species and the dispersed pollutants was proposed [12]. Other mathematical models were proposed by our group [13-15], although their main characteristics are going to be summarized in the next section because they constitute the base of the model which is going to be presented in this work.

In previous works of this group [16-18], it has been studied the behaviour of electrocoagulation of arsenates, phosphates and nitrates in water, reporting the main processes with conceptual models. However, a mathematical description was not done. For this reason, the main goal of this work is to develop a mathematical model for the electrocoagulation of arsenates, phosphates and nitrates in water by adapting previous models developed for electro-coagulation to this particular case (removal of anions), and to use this model in order to get an economic evaluation of the treatment processes focused on 
knowing the raw material and energy costs which are necessary to remove anionic pollutants from water.

\section{Mathematical model for the electro-coagulation of arsenates, nitrates and phosphates}

The model proposed in this work is based on a simplified model reported in literature $[14,15]$ for the electro-coagulation of wastewaters with aluminium electrodes. The model was based on several assumptions concerning the cell description, the aluminium and pollutant speciation and the main reaction mechanisms. This model also considered that the interactions between pollutant and coagulant species could be described by pseudo-equilibrium equations. The model was successfully applied to the electrocoagulation of kaolin colloids suspensions, Eriochrome black T dyes solutions and oilin-water emulsions, and it gave a very accurate description of the treatment results.

\subsection{Model assumptions}

The model proposed in this work is based on the same assumptions, although several of them have been enlarged in order to consider not only aluminium electro-coagulation but also iron electro-coagulation. These hypotheses are related to the cell description, the fluid dynamic conditions, the coagulant speciation (general assumptions), and the interaction between pollutants and coagulant reagents (specific assumptions).

Concerning to the cell description, the general model is based on the following approach:

- The fluid-dynamic model for the electrochemical cell is a macroscopic approach, which considers that the parameters depend only on time and not on position. Therefore, this model does not take into account the mass transport conditions (convection, migration or diffusion) that occur in the cell. This description markedly decreases the mathematical complexity of the system and idealizes the cell as a perfectly mixed flow reactor.

In relation to the coagulant speciation, the general model (including both aluminium and iron electro-coagulation) is based on the following statements:

- The concentration of the different coagulant species generated in the reaction medium (as a consequence of the electrode dissolution) depends on the $\mathrm{pH}$ and 
the total dissolved metal concentration. These values can be calculated by pseudo-equilibrium approaches, as reported in a previous publication of our group [13]. This previous model considers eight equilibrium equations and calculates six actual metal species $\left[\mathrm{M}^{3+}, \mathrm{M}(\mathrm{OH})^{2+}, \mathrm{M}(\mathrm{OH})_{2}{ }^{+}, \mathrm{M}(\mathrm{OH})_{3}\right.$ sol (soluble), $M(\mathrm{OH})_{3}$ pre (precipitate), $\left.\mathrm{M}(\mathrm{OH})_{4}^{-}\right]$. The details of the mathematical resolution of this system of equations are given elsewhere [13]. The actual dissolved metal species are classified into five model categories, or coagulant species, in the model (according to the coagulation mechanisms proposed in the work):

- $M_{0}$ stands for the total electro-dissolved metal concentration in terms of $\mathrm{Al}(\mathrm{III})_{\text {total }}$ or $\mathrm{Fe}(\mathrm{III})_{\text {total }}$;

- $M_{1}$ represents the metal in the form of precipitates and corresponds to $M(O H)_{3}$ pre from the actual species;

- $M_{2}$ corresponds to the metal species that are not useful in the coagulation processes, i.e., the soluble metal hydroxide $\mathrm{M}(\mathrm{OH})_{3}$ sol and the cationic and anionic species $\left[\mathrm{M}^{3+}, \mathrm{M}(\mathrm{OH})^{2+}, \mathrm{M}(\mathrm{OH})_{2}{ }^{+}\right.$and $\left.\mathrm{M}(\mathrm{OH})_{4}^{-}\right]$. It is obtained from the actual species.

All of these model species are expressed in $\mathrm{mg} \mathrm{dm}^{-3}$. The total electro-dissolved metal, $M_{0}$ concentration $\left(\mathrm{Al}(\mathrm{III})_{\text {total }}\right.$ or $\mathrm{Fe}(\mathrm{III})_{\text {total }}$ ), is expressed by Equation 1 .

$$
\mathrm{M}_{0}=\mathrm{M}_{1}+\mathrm{M}_{2}
$$

In the case of iron electro-coagulation process, at low values of electric charge applied $\left(Q_{i}<Q_{\max }\left(\mathrm{Q}, \mathrm{Ah} \mathrm{dm}^{-3}\right)\right) \mathrm{Fe}(\mathrm{II})$ species have to be considered in the model due to their significant influence on the direct precipitation (or charge neutralization) of anionic pollutants [16,18]. Therefore, $\mathrm{Fe}(\mathrm{II})$ and $\mathrm{Fe}$ (III) species are taken into account in the model, and $\mathrm{Fe}_{\text {total }}=\mathrm{Fe}(\mathrm{III})_{\text {total }}+\mathrm{Fe}(\mathrm{III})_{\text {total }}$. Regarding Fe(II) species, they are divided into: $M_{3}$ which corresponds to free $\mathrm{Fe}$ (II) species whereas $M_{4}$ is the $\mathrm{Fe}(\mathrm{II})$ which directly precipitates with anionic pollutants. Thus, an $\alpha$ parameter is introduced in the model to relate $M_{0}$ (or $\left.\mathrm{Fe}(\mathrm{III})_{\text {total }}\right)$ to the total amount of iron $\left(\mathrm{Fe}_{\text {total }}\right), M_{3}$ and $M_{4}$ by means of equations 2 to 4 . 


$$
\begin{aligned}
& \alpha=\frac{\mathrm{Q}_{\mathrm{i}}}{\mathrm{Q}_{\max }}, \quad \frac{\mathrm{Q}_{\mathrm{i}}}{\mathrm{Q}_{\text {max }}} \leq \alpha \leq 1 \\
& \mathrm{M}_{0}=\mathrm{Fe}_{\text {total }} \cdot \alpha \\
& \mathrm{Fe}_{\text {total }}=\frac{\mathrm{M}_{0}}{\alpha}=\mathrm{M}_{0}+\mathrm{M}_{3}+\mathrm{M}_{4}=\mathrm{M}_{1}+\mathrm{M}_{2}+\mathrm{M}_{3}+\mathrm{M}_{4}
\end{aligned}
$$

- The effects due to the matrix solution generated by the electrolyte species (especially sulphate or chloride) are not considered to influence the electrodissolved metal speciation.

- In a similar way to the coagulant species, the pollutant species need to be classified into different categories (pollutant species of the model). The classification depends on the type of pollutant and on the reactivity of these model species with the different coagulant species. Therefore, the classification has to be made according to the description of the coagulation mechanisms considered in the model for each type of wastewater.

- The reactive processes involving coagulant and pollutant species are assumed to develop rapidly and they are modelled by pseudo-equilibrium approaches. Hence, the model proposes a system that is in a quasi-equilibrium state at all times, and any modification in the amounts of coagulant or pollutant species causes the evolution of the system towards a new equilibrium state.

\subsection{Speciation of pollutants and reaction pathways in the electro-coagulation of} arsenates, nitrates and phosphates in water

In order to model the electro-coagulation of anions, a more detailed description of the pollutants' speciation and the interaction between pollutants and coagulant reagents should be developed. In the treatment of wastewaters polluted with inorganic anions, the specific assumptions that should be considered are as follows:

- According to previous works [16-18], the main coagulation mechanisms that can explain the experimental observations for the electro-coagulation of anions with iron or aluminium are (i) the direct precipitation of anions and (ii) the adsorption or enmeshment of the inorganic anions within a growing iron or aluminium hydroxide precipitate. 
- The anionic pollutants undergo ionization in water, and the level of ionization depends on the $\mathrm{pH}$. The model speciation of anionic pollutants (AP) (that can be found as different ionized species in the aqueous solution) considers the following contributions:

- $A P_{0}$ represents the total anionic pollutant concentration of the solution.

- $A P_{1}$ corresponds to the refractory anionic pollutant concentration, i.e., the concentration that cannot be removed by electro-coagulation processes.

- $A P_{2}$ expresses the concentration of anionic pollutant removed by direct precipitation (charge neutralization) under given operating conditions.

- $A P_{3}$ denotes the anionic pollutant concentration eliminated by adsorption or enmeshment in a precipitate under given conditions.

- $A P_{4}$ represents the remaining concentration of anionic pollutant, i.e., the concentration that can be removed but is not under the given set of conditions.

According to the speciation, the total concentration of anionic pollutant and the amount of anionic pollutant eliminated $\left(A P_{e}\right)$ in each experiment can be expressed as Equations 5 and 6.

$$
\begin{aligned}
& \mathrm{AP}_{0}=\mathrm{AP}_{1}+\mathrm{AP}_{2}+\mathrm{AP}_{3}+\mathrm{AP}_{4} \\
& \mathrm{AP}_{\mathrm{e}}=\mathrm{AP}_{2}+\mathrm{AP}_{3}
\end{aligned}
$$

- The mechanism of direct precipitation (or neutralization) of anionic pollutants by $\mathrm{Fe}(\mathrm{II})$ species is expressed by an equilibrium reaction, according to Equations 7 and 8, where $n$ stands for the overall coefficient of direct precipitation [expressed in $\left.\left(\mathrm{mg} \mathrm{AP} \mathrm{dm}^{-3}\right) /\left(\mathrm{mg} \mathrm{M} \mathrm{dm}^{-3}\right)\right]$. The parameter $n$ is not constant and its value is related to the charges present in the solution [12]. $A P_{2}$ can be calculated by Equation 8. The equilibrium constant is $K_{1}$ and is defined by Equation 9.

$$
\begin{aligned}
& \mathrm{AP}_{4}+\mathrm{n} \mathrm{M}_{3} \rightleftarrows \mathrm{AP}_{2}+\mathrm{M}_{4} \quad \mathrm{~K}_{1} \\
& \mathrm{AP}_{2}=\mathrm{n} \cdot \mathrm{M}_{4} \\
& \mathrm{~K}_{1}=\frac{\mathrm{AP}_{2}}{\mathrm{M}_{3} \cdot \mathrm{AP}_{4}}
\end{aligned}
$$


Here, it is worth to mention that the mechanism of direct precipitation of nitrates by $\mathrm{Fe}(\mathrm{II})$ species is noticed to be not significant in experimental results because the requirement of electric charge applied to remove nitrates is much higher in comparison with arsenates or phosphates removal processes [17]. Furthermore, according to experimental data [16-18], the mechanism of neutralization of anionic pollutants by cationic $\mathrm{Al}(\mathrm{III})$ or $\mathrm{Fe}(\mathrm{III})$ species is observed to be negligible due to its small influence on the overall electro-coagulation process.

- The adsorption or enmeshment of anionic pollutants into a growing aluminium or iron precipitate (sweep floc) can be expressed by Equation 10. Parameter $m$ is the overall coefficient of adsorption (or enmeshment) of the AP on a precipitate [expressed in $\left.\left(\mathrm{mg} \mathrm{AP} \mathrm{dm}^{-3}\right) /\left(\mathrm{mg} \mathrm{M} \mathrm{dm}^{-3}\right)\right]$, and this can be estimated from the experimental observations. $A P_{3}$ can be calculated with Equation 11.

$$
\begin{aligned}
& \mathrm{AP}_{4}+\mathrm{m} \mathrm{M}_{1} \rightleftarrows \mathrm{AP}_{3} \\
& \mathrm{AP}_{3}=\mathrm{m} \cdot \mathrm{M}_{1}
\end{aligned}
$$

Rearrangement of the mass balances of aluminium (eq. 1) or iron (eq. 4) and anionic pollutant (eq. 5) (together with eq. 11 for aluminium electro-coagulation and equations 8,9 and 11 for iron electro-coagulation) lead to the expressions shown in equation 12 for aluminium and in equations 13 and 14 for iron.

$$
\begin{aligned}
& \mathrm{AP}_{4}=\mathrm{AP}_{0}-\mathrm{AP}_{1}-\mathrm{m} \cdot \mathrm{M}_{1} \\
& \mathrm{AP}_{4}=\frac{\mathrm{AP}_{0}-\mathrm{AP}_{1}-\mathrm{m} \cdot \mathrm{M}_{1}}{1+\mathrm{K}_{1} \cdot \mathrm{M}_{3}} \\
& \mathrm{M}_{3}=\frac{\frac{\mathrm{M}_{0}}{\alpha}-\mathrm{M}_{1}-\mathrm{M}_{2}}{1+\frac{\mathrm{K}_{1} \cdot \mathrm{AP}_{4}}{\mathrm{n}}}
\end{aligned}
$$

The values of $A P_{2}, A P_{3}$ and $A P_{4}$ can be easily calculated from equation 12 for aluminium and from equations 13 and 14 for iron.

\section{Experimental details}

\subsection{Experimental procedures}


Batch electro-coagulation experiments have been carried out in a bench-scale plant shown elsewhere [18]. The coagulant reagent was obtained through the dissolution of the iron or aluminium electrodes placed in a single-compartment electrochemical flow cell. Both electrodes (anode and cathode) were square in shape $\left(100 \mathrm{~cm}^{2}\right)$, and the electrode gap was $9 \mathrm{~mm}$. The electrical current was applied using a DC power supply (FA-376 PROMAX). The current flowing through the cell was measured with a Keithley 2000 digital multimeter. The range of current density studied was from 0.1 to $5.0 \mathrm{~mA} \mathrm{~cm}$, and experiments were carried out galvanostatically. The synthetic wastewater was stored in a glass tank $\left(5000 \mathrm{~cm}^{3}\right)$ stirred by a Heidolph RZR 2041 overhead stainless steel rod stirrer and recirculated through the electrolytic cell using a peristaltic pump.

In the case of the arsenic polluted waters, the synthetic water is composed by sodium arsenate $\left(20 \mathrm{mg} \mathrm{AsO}{ }_{4}^{-3}-\mathrm{As} \mathrm{dm}^{-3}\right)$ and a supporting electrolyte to increase its conductivity (1000 $\left.\mathrm{mg} \mathrm{NaCl} \mathrm{dm}{ }^{-3}\right)$.

The synthetic groundwater polluted with nitrate consisted of sodium nitrate $(25 \mathrm{mg}$ $\mathrm{NO}_{3}{ }^{-}-\mathrm{N} \mathrm{dm}^{-3}$ ) and a supporting electrolyte in order to increase its conductivity (3000 $\mathrm{mg} \mathrm{dm}{ }^{-3} \mathrm{Na}_{2} \mathrm{SO}_{4}$ ). This nitrate concentration is reported to be the average concentration of nitrates into groundwater in agriculture zones which have an excessive use of fertilizers $[19,20]$.

In the case of phosphate polluted waters the synthetic water was composed of sodium phosphate $\left(27 \mathrm{mg} \mathrm{PO}_{4}{ }^{-3}-\mathrm{P} \mathrm{dm}^{-3}\right.$ ) as $\mathrm{Na}_{3} \mathrm{PO}_{4} \cdot \mathrm{H}_{2} \mathrm{O}$ and a supporting electrolyte to increase its conductivity (500 $\mathrm{mg} \mathrm{dm}^{-3} \mathrm{Na}_{2} \mathrm{SO}_{4}$ ).

\subsection{Analysis procedure}

The total arsenic concentration was measured off-line using an inductively coupled plasma mass spectrometry with a quadrupole ICP-MS operated in a $\mathrm{He} / \mathrm{H}_{2}$ cell mode (Agilent HP 7500c, University of Oviedo). Nitrate and phosphate concentrations were determined by ion chromatography using a Shimadzu LC-20A system by means of a Shodex IC I-524A column for anionic separation. The total aluminium or iron concentrations were measured off-line using an inductively coupled plasma Liberty Sequential Varian system. These analyses were carried out according to the standard methods [21], and have been described elsewhere [16-18]. 


\section{Results and discussion}

\subsection{Electro-coagulation model results for removal of arsenates, phosphates and}

nitrates

An optimization procedure was used to obtain a set of parameters that allows simulation with the model. In the mathematical model proposed to reproduce the iron electrocoagulation of waters polluted with inorganic anions, the model parameters $Q_{\max }$ and $K_{l}$ were estimated by best fitting of the experimental variations of AP eliminated $\left(A P_{e}\right)$ in the electro-coagulation process as a function of the $\mathrm{pH}$. The best values obtained for these last parameters are summarized in Table 1. Preliminary simulations showed that (except for the parameters $n$ and $m$ ) a unique value for all parameters can be used to reproduce all of the experimental observations.

Parameter $n\left[\left(\mathrm{mg} \mathrm{AP} \mathrm{dm}^{-3}\right) /\left(\mathrm{mg} \mathrm{M} \mathrm{dm}^{-3}\right)\right]$ is the overall coefficient of direct precipitation of AP by Fe(II) species, indicating the amount of AP that can be removed by this coagulation mechanism for a given concentration of iron. The parameter $n$ has a marked influence on the AP results and a unique value of this parameter cannot explain all of the experimental observations. Thus, in this work it has been proposed that parameter $n$ could be estimated by the empirical Equation 15, in which the effect of $\mathrm{pH}$ on speciation is considered. In previous paragraphs, the direct precipitation mechanism was commented to not have a significant contribution in the removal of nitrates by electro-coagulation whereas the removal of arsenates and phosphates by direct precipitation with $\mathrm{Fe}(\mathrm{II})$ species has an important contribution to remove these anionic pollutants at low values of electric charge applied [16-18]. Likewise, arsenates and phosphates are known to be dissociated in solution as a function of actual $\mathrm{pH}$, which ranges from 5 to 12 according to experimental observations (for this reason $\mathrm{x}_{1}$ and $\mathrm{x}_{2}$ are set to 5 and 12 respectively in equation 15 for estimation of $n$ ). The least dissociated anionic pollutant species which can be present in solution are $\mathrm{H}_{2} \mathrm{AsO}_{4}{ }^{-}$or $\mathrm{H}_{2} \mathrm{PO}_{4}{ }^{-}$and the most dissociated anionic pollutants can be $\mathrm{AsO}_{4}{ }^{3-}$ or $\mathrm{PO}_{4}{ }^{3-}$. These last anionic pollutant species would directly precipitate with $\mathrm{Fe}(\mathrm{II})$ species in a theoretical range from 0.67 to $2.01[(\mathrm{mg} \mathrm{As}) /(\mathrm{mg} \mathrm{Fe})]$ for arsenate electro-coagulation whereas in phosphate electro-coagulation, this theoretical range is between 0.28 and $0.83[(\mathrm{mg} \mathrm{P}) /$ (mg Fe)] (according to the possible stoichiometry of the precipitation reactions, i.e.: between 1 and $3 \mathrm{~mol}$ of $\mathrm{P}$ or As per $2 \mathrm{~mol}$ of $\mathrm{Fe}$ ). Furthermore, it is worth to mention 
that arsenates and phosphates do not have the same availability to precipitate (in fact they should have different precipitation constants) and for that reason, parameter $n$ has to be corrected by a fitting parameter $c$, which depends on the anion. The best estimates for $c$ are 0.1 in the case of working with arsenates solutions and 0.6 in the case of working with phosphate solutions. With this, parameters shown in Equation 15 are summarized in Table 2, depending on anionic pollutant treated.

$$
\mathrm{n}=\left(\mathrm{y}_{1}+\frac{\mathrm{y}_{2}-\mathrm{y}_{1}}{\mathrm{x}_{2}-\mathrm{x}_{1}} \cdot\left(\mathrm{pH}-\mathrm{x}_{1}\right)\right) \cdot \mathrm{c}
$$

Parameter $m\left[\left(\mathrm{mg} \mathrm{AP} \mathrm{dm}^{-3}\right) /\left(\mathrm{mg} \mathrm{M} \mathrm{dm}^{-3}\right)\right]$ is the overall coefficient of adsorption (or enmeshment) of the AP on aluminium or iron precipitate, indicating the amount of AP that can be removed by this coagulation mechanism for a given concentration of coagulant. The parameter $m$ also has a marked influence on the AP results and a unique value of this parameter cannot explain all of the experimental observations. However, a significant relationship is observed with the magnitude of charges present in the solution. A parameter called $C_{n}$ (net charge, expressed in $\mathrm{mol} \mathrm{dm}^{-3}$ ) is therefore introduced to quantify the magnitude of the charges in the solution. This parameter consists of the net sum of the charge of each ionic species present in the system and can be calculated by Equation 16 , where $\left[\mathrm{M}^{3+}\right],\left[\mathrm{M}(\mathrm{OH})^{2+}\right],\left[\mathrm{M}(\mathrm{OH})_{2}{ }^{+}\right]$and $\left[\mathrm{M}(\mathrm{OH})_{4}^{-}\right]$are the molar concentrations of the actual coagulant species and $\left[\mathrm{H}^{+}\right]$and $\left[\mathrm{OH}^{-}\right]$are the molar concentrations of protons and hydroxyl ions, under given conditions.

$$
\mathrm{C}_{\mathrm{n}}=3 \cdot\left[\mathrm{M}^{3+}\right]+2 \cdot\left[\mathrm{M}(\mathrm{OH})^{2+}\right]+\left[\mathrm{M}(\mathrm{OH})_{2}^{+}\right]+\left[\mathrm{H}^{+}\right]-\left[\mathrm{M}(\mathrm{OH})_{4}{ }^{-}\right]-\left[\mathrm{OH}^{-}\right]
$$

It has been found that parameter $m$ vs. absolute value of $C_{n}$ fits well to a potential function for iron electro-coagulation process while it is a logarithmic function for aluminium one, as can be seen in Figure 1a (iron electro-coagulation) and $1 \mathrm{~b}$ (aluminium electro-coagulation).

Thus, the value of parameter $m$ can be estimated by equations 17 (iron electrocoagulation) and 18 (aluminium electro-coagulation). Estimated parameters for equations 17 and 18 are summarized in Table 3.

$$
\mathrm{m}=\mathrm{a} \cdot\left(\left|\mathrm{C}_{\mathrm{n}}\right|\right)^{\mathrm{b}}
$$




$$
\mathrm{m}=\mathrm{a} \cdot \ln \left|\mathrm{C}_{\mathrm{n}}\right|+\mathrm{b}
$$

To illustrate the accuracy of the model, some experimental results (corresponding to the treatment of phosphates) obtained in the iron electro-coagulation processes at different values of current density are shown in Figure 2a, where they are compared to those obtained from the model proposed. Likewise, the experimental and modelled values for the removal of phosphate from water by aluminium electro-coagulation processes are represented in Figure 2b.

In all cases, the model is observed to fit satisfactorily the experimental data. These observations support the assumptions on which the model is based. However, to get a proper validation analysis modelled data should be represented against experimental data and regression coefficients should be taken into account. These plots are shown in Figure 3 for iron electro-coagulation and Figure 4 for aluminium electro-coagulation. Obviously, the model would ideally describe the process if all points lay over the line $\mathrm{Y}_{\text {experimental }}=\mathrm{y}_{\text {modelled }}$.

Likewise, the regression coefficient is used to compare the actual values of the outputs of the process with the values proposed by the model (in fact it is the same information but summarized in just one parameter). The higher the regression coefficient, the better the reproducibility is obtained. The regression coefficient is calculated by Equation 19, where $y_{i}$ states for the experimental values of the output, $\hat{y}_{i}$ are the model values and $\bar{y}$ is the average value of the experimental outputs used in the validation.

$$
\mathrm{r}^{2}=1-\frac{\sum_{\mathrm{i}=1}^{\mathrm{N}}\left(\mathrm{y}_{\mathrm{i}}-\hat{y}_{i}\right)^{2}}{\sum_{\mathrm{i}=1}^{\mathrm{N}}\left(\mathrm{y}_{\mathrm{i}}-\bar{y}\right)^{2}}
$$

The regression coefficients $\left(r^{2}\right)$ of each set of data are included in figures 3 and 4 . It can be observed that in most of the cases studied the regression coefficients are higher than 0.90 which is indicative of the good reproducibility of the model. This finding, together with the small number of parameters needed, supports the robustness of the model proposed and validates the assumptions on which it is based.

\subsection{Coupling mathematical modelling and cost analyses for the electro-coagulation} of arsenates, phosphates and nitrates 
The operating costs of the electro-coagulation process involve the estimation of many items, being two of the most important, and at the same time the most distinctive, the price of the iron or aluminium sheets (used as electrodes) dissolved to produce coagulant reagents and the energy costs for their electro-dissolution [22]. In this context, this study aims to be just a preliminary economical evaluation focused on knowing the raw material and energy costs which are necessary to remove anionic pollutants from water, but it does not aim to estimate the total cost of the overall process.

Different initial concentrations of each anionic pollutant have been proposed in order to determine by the mathematical model developed in this work, the coagulant dose required and the electricity consumption necessary to remove these anionic pollutants until a fixed limit.

To fix the target of the electro-coagulation treatment in terms of concentration of pollutant anions, regulations of the Spanish government have been used. Thus, according to REAL DECRETO 1620/2007 (more restrictive than the Spanish regulation for tap water and obviously than the regulation for the discharge of wastewater into environment), which is used to regulate the reuse of treated waters, nitrogen should be restricted to $10 \mathrm{mg} \mathrm{dm}^{-3}$ while phosphorous should be limited to $1 \mathrm{mg} \mathrm{dm}^{-3}$ in reused water to avoid environmental and health problems. Likewise, the maximum arsenic concentration which should be present in drinking water is $10 \mu \mathrm{g} \mathrm{dm}^{-3}$ taking into account the limits fixed by REAL DECRETO 140/2003.

With respect to the cases studied, a very wide concentrations-range of anionic pollutants have been proposed in this study, in order to cover the typical concentrations of these pollutants in ground or superficial waters, and also in industrial, urban or domestic wastewaters. The initial anionic pollutant concentrations proposed are: 1, 10 and 100

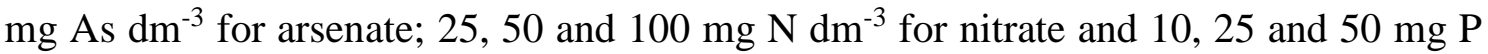
$\mathrm{dm}^{-3}$ for phosphate. To estimate costs, they are fed to the mathematical model to obtain the coagulant dose required and the energy consumption in each case proposed. The $\mathrm{pH}$ values have been proposed according to the $\mathrm{pHs}$ obtained after the treatment in the experiments whose results have been previously reported [16-18] (pHs proposed are shown in Table 4 in case of arsenate removal, and in tables S1 and S2 in Supplementary data for nitrate and phosphate). 
In the electro-coagulation processes, the raw material costs involve the price of the iron or aluminium quantity that is required to remove initial concentration of anionic pollutants until the desired final concentration. The price of aluminium sheets ( $\mathrm{Al} \mathrm{1050)}$ of $2 \times 1 \mathrm{~m}$ of size, with $0.8 \mathrm{~mm}$ of thickness is around $3.85 € \mathrm{Kg}^{-1} \mathrm{Al}$ (obtained from commercial budgets). Likewise, the price of iron sheets (C67S) of $2 \times 1 \mathrm{~m}$ of size, with $1.5 \mathrm{~mm}$ of thickness is around $1.24 € \mathrm{Kg}^{-1} \mathrm{Fe}$ (obtained from commercial budgets). The mathematical model developed in this work lets to obtain an iron or aluminium concentration which meets the experimental conditions proposed (in the different cases). Thus, knowing the coagulant concentration $\left(\mathrm{mg} \mathrm{dm}^{-3}\right)$ required in each case proposed and the price of coagulant sheets $\left(€ \mathrm{Kg}^{-1}\right)$, the raw material costs $\left(\mathrm{c} € \mathrm{~m}^{-3}\right)$ can be calculated taking into account the requirement of the unit conversion in each parameter. These raw material costs are summarized in Table 4 in case of arsenate removal, and in tables S1 and S2 in Supplementary data for nitrate and phosphate removal.

Results show that, as it can be expected, the higher initial anionic pollutant concentration, the higher raw material costs is, because of the higher coagulant required-dose to remove anionic pollutants from water down to the fixed limit. It can also be observed that raw-material costs of iron electro-coagulation process are lower than those of aluminium for the same experimental conditions. In addition, arsenate removal is the most efficient in terms of raw-matter consumption and nitrate removal is significantly more expensive than removal of phosphates and arsenates.

The energy costs associated to the iron or aluminium electro-dissolution can be evaluated by Equation 20. As reported in literature [13, 23], energy required to develop the electro-dissolution process is highly dependent on the current density applied. Taking this into account, energy costs have been calculated for a range of current densities from 0.2 to $4.0 \mathrm{~mA} \mathrm{~cm}$, which is a typical range used in electro-coagulation processes.

Energetic costs $\left(c € m^{-3}\right)=\mathrm{Q}\left(A h d m^{-3}\right) \cdot \mathrm{V}($ volts $) \cdot 0.11\left(€ k W h^{-1}\right) \cdot 100$

where the electric charge applied $(Q)$ is calculated by Equation 21, which comes from a metal mass balance to the electro-coagulation cell. 
$\mathrm{Q}\left(A h d m^{-3}\right)=\frac{[\mathrm{M}]\left(m g M d m^{-3}\right) \cdot \mathrm{j}\left(m A \mathrm{~cm}^{-2}\right) \cdot 10}{\mathrm{~A}\left(m m o l M h^{-1} m^{-2}\right) \cdot \mathrm{M} W_{\mathrm{M}}\left(m g M(m m o l ~ M)^{-1}\right)}$

The parameter $A$ [mmol $M \mathrm{~h}^{-1} \mathrm{~m}^{-2}$ ] showed in Equation 21 represents the influence of the current density on the coagulant dissolution rate in the electro-coagulation process (Figure 5a). It differs from the theoretical behaviour predicted by the Faraday's Law, especially in case of aluminium electro-dissolution, as it has been previously reported by our group $[13,18]$.

According to data shown in Figure 5a, parameter $A$ can be calculated by an empirical model given by Equation 22 for aluminium electro-coagulation and Equation 23 for iron electro-coagulation, where $j\left[\mathrm{~mA} \mathrm{~cm}^{-2}\right]$ is the current density applied.

$$
\begin{aligned}
& A=191.21 \cdot j+54.061 \\
& A=74.076 \cdot j+16.915
\end{aligned}
$$

In addition, the voltage $[V($ volts $)]$ is also related to current density as shown in Figure $5 \mathrm{~b}$, which shows experimental data previously reported [16-18] that have been used to obtain an empirical model for aluminium electro-coagulation (Equation 24) and for iron electro-coagulation (Equation 25), where $j\left[\mathrm{~mA} \mathrm{~cm}^{-2}\right]$ is the current density applied.

$$
\begin{aligned}
& V=0.3498 \cdot j+0.5995 \\
& V=0.5983 \cdot j+0.9147
\end{aligned}
$$

Once calculation of parameters shown in Equation 20 has already been done, the energy costs can be estimated taking into account that the electricity cost for industrial use in Spain is around $0.11 € \mathrm{kWh}^{-1}$. Thus, the energy costs are summarized in Table 4 for arsenate removal, and in tables S1 and S2 in Supplementary data for nitrate and phosphate removal, under conditions proposed and in a range of current density from 0.2 to $4.0 \mathrm{~mA} \mathrm{~cm}^{-2}$.

Results shown indicate that the higher current density, the higher energy costs are, due to the increase of voltage with current density. Likewise, energy costs are higher for iron electro-coagulation processes than for aluminium ones. Obviously, the higher initial anionic pollutant concentration, the higher energy costs to reduce pollutant concentration down to the target values fixed. In addition, as happened with raw 
material costs, arsenate removal is observed to be cheaper in terms of energy costs than phosphate removal. Likewise, both treatments are broadly cheaper than that of nitrate removal.

Finally, by adding the raw material and energy costs, an estimation of the total operating cost is obtained. These results are represented in Figure 6. In this Figure, only the two boundary current densities $\left(0.2\right.$ and $\left.4.0 \mathrm{~mA} \mathrm{~cm}^{-2}\right)$ have been drawn in order to clearly discern the points represented. It is also worth to say that data are represented in $\log -\log$ scale to facilitate the examination of the whole range of concentrations evaluated.

Results clearly show that iron electro-coagulation is cheaper than aluminium electrocoagulation being differences particularly important in the case of phosphate. This means that iron can be for sure the recommended choice in most cases. In addition and as expected, the higher the concentration of pollutant (and hence the amount of pollutant to be removed) the higher the operating cost is (potential increase because of the linear fitting in a log-log plot). Inside the current density range used, there is not a very significant influence of this parameter on the cost, although always it is cheaper to work at low current densities.

With respect to the applications, removal of arsenate seems to be particularly attractive, because in addition to its great social demand, electro-coagulation results in smaller cost as compared to the removal of phosphate and nitrates. The great effectiveness on the removal of arsenate of the iron and aluminium dosed electrochemically can be responsible of this positive observation. In this case, the technical feasibility of the coagulation is smaller and hence electro-coagulation does not compete with it [16]. The same applies for phosphate removal in which from the technical point of view, the quality reached by electro-coagulation cannot be obtained by coagulation [18]. On the opposite, nitrate removal seems to be very expensive by electro-coagulation also because of the low efficiency in the use of reagent dosed (in this case there are other cheaper competing technologies, different from coagulation).

As stated before a comparison with the cost proposed by other authors is not worth because it will not be done for sure in the same conditions. Anyhow, operating costs are in the same order of magnitude than those found in literature for arsenates [24], although the model proposed in this work results in some lower operating costs for the 
same experimental conditions. To make a figure about cost for every application, for a typical pollutant concentration inside the ranges of pollutant concentration studied in

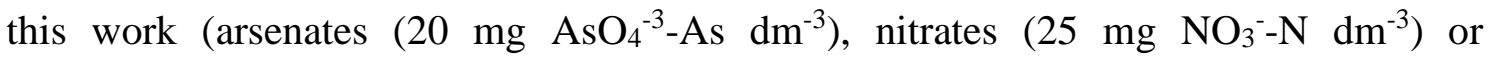
phosphates $\left(27 \mathrm{mg} \mathrm{PO}_{4}^{-3}-\mathrm{P} \mathrm{dm}^{-3}\right.$ ), and for the treatment targets fixed in the Spanish regulation, operating cost of iron electro-coagulation are 2.5, 109.6 and $5.4 \mathrm{c} € \mathrm{~m}^{-3}$. Taking into account them, the removal of nitrates by electro-coagulation cannot be advised, whereas the use of the electro-coagulation in the removal of phosphates presents good economic prospects. Here, literature reports that the average operating cost to remove nutrients in wastewater treatment facilities by biological technology is of $2.9 \mathrm{c} € \mathrm{~m}^{-3}$ to remove phosphorous and it was $14.3 \mathrm{c} € \mathrm{~m}^{-3}$ for the removal of nitrogen [25]. On the contrary, the process which appears technically and economically more interesting is the removal of arsenate by electro-coagulation in comparison to other technologies such as the in situ precipitated ferric and manganese binary oxides adsorption, sand filtration, and ultra-filtration for arsenic removal with an operating cost of $4.3 \mathrm{c} € \mathrm{~m}^{-3}[26]$

\section{Conclusions}

From the results discussed in this work the following conclusions can be drawn:

- The iron and aluminium electro-coagulation treatments of waters polluted with arsenates, nitrates and phosphates can be easily modelled using a semiphenomenological model based on a macroscopic approach for the fluid-dynamic behaviour (idealizing the cell as a perfectly mixed flow reactor), three model aluminium species or five model iron species (related to the total coagulant concentration and $\mathrm{pH}$ ), five model pollutant species (related to the main coagulation mechanisms) and a proposal for the main reaction mechanisms.

- The direct precipitation of AP with iron(II) species and the enmeshment of AP species in a growing coagulant (iron(III) or $\mathrm{Al}(\mathrm{III})$ ) hydroxide precipitate are considered as the main mechanisms. The model uses four fitting parameters: $Q_{\max }$, $K_{l}, n$ and $m$. For $Q_{\max }$ and $K_{l}$, a single value explains all of the experimental observations. The value of $n$ is related to the $\mathrm{pH}$ and the value of $\mathrm{m}$ to $C_{n}$ by means of simple equations. Good agreement is obtained between experimental and modelled results, with a global regression coefficient $\left(\mathrm{r}^{2}\right)$ above 0.90 in most cases studied. 
The operating costs of the electro-coagulation process depend on concentration of pollutants. The electro-coagulation with iron electrodes at low values of current density is the most economical process for removing the three pollutants studied.

- According to obtained results, removal of arsenate seems to be technically and economically more interesting. The same applies for phosphate removal in which operation cost seems reasonable. On the opposite, nitrate removal seems to be very expensive by electro-coagulation, because of the low efficiency in the use of reagent dosed electrochemically.

\section{Acknowledgements}

This work was supported by the MCT (Ministerio de Ciencia y Tecnología, Spain) and by the EU (European Union) through projects CTM2007-60472/TECNO, CTM201018833/TECNO and through the CONSOLIDERINGENIO 2010 (CSD2006-044) project. 


\section{References}

[1] N. Mameri, H. Lounici, D. Belhocine, H. Grib, L.D. Piron, Y. Yahiat, Defluoridation of Sahara water by small plant electrocoagulation using bipolar aluminium electrodes, Sep. Purif. Technol. 24 (2001) 113-119.

[2] M.A. Rodrigo, P. Cañizares, C. Buitrón, C. Sáez, Electrochemical technologies for the regeneration of urban wastewaters, Electrochim. Acta 55 (2010) 8160-8164.

[3] C. Ahmed Basha, S. Josephine Selvi, E. Ramasamy, S. Chellammal, Removal of arsenic and sulphate from the copper smelting industrial effluent, Chem. Eng. J. 141 (2008) 89-98.

[4] X. Chen, G. Chen, P.L. Yue, Separation of pollutants from restaurant wastewater by electrocoagulation, Sep. Purif. Technol. 19 (2000) 65-76.

[5] H. Bergmann, A. Rittel, T. Iourtchouk, K. Schoeps, K. Bouzek, Electrochemical treatment of cooling lubricants, Chem. Eng. Process. 42 (2003) 105-119.

[6] A.K. Golder, N. Hridaya, A.N. Samanta, S. Ray, Electrocoagulation of methylene blue and eosin yellowish using mild steel electrodes, J. Hazard. Mater. 127 (2005) 134-140.

[7] Z. Zaroual, M. Azzi, N. Saib, E. Chainet, Contribution to the study of electrocoagulation mechanism in basic textile effluent, J. Hazard. Mater. 131 (2006) 73-78.

[8] M.Y.A. Mollah, R. Schennach, J.R. Parga, D.L. Cocke, Electrocoagulation (EC) science and applications, J. Hazard. Mater. B 84 (2001) 29-41.

[9] G. Chen, Electrochemical technologies in wastewater treatment, Sep. Purif. Technol. 38 (2004) 11-41.

[10] M.Y.A. Mollah, P. Morkovsky, J.A.G. Gomes, M. Kesmez, J. Parga, D.L. Cocke, Fundamentals, present and future perspectives of electrocoagulation, J. Hazard. Mater. B 114 (2004) 199-210.

[11] M. Carmona, M. Khemis, J.P. Leclerc, F. Lapicque, A simple model to predict the removal of oil suspensions from water using the electrocoagulation technique, Chem. Eng. Sci. 61 (2006) 1233-1242. 
[12] M. Khemis, J.P. Leclerc, G. Tanguy, G. Valentin, F. Lapicque, Treatment of industrial liquid wastes by electrocoagulation: experimental investigations and an overall interpretation model, Chem. Eng. Sci. 61 (2006) 3602-3609.

[13] P. Cañizares, M. Carmona, J. Lobato, F. Martínez, M.A. Rodrigo, Electrodissolution of aluminum electrodes in electrocoagulation processes, Ind. Eng. Chem. Res. 44 (2005) 4178-4185.

[14] P. Cañizares, F. Martínez, M.A. Rodrigo, C. Jiménez, C. Sáez, J. Lobato, Modelling of wastewater electrocoagulation processes Part I: General description and application to kaolin-polluted wastewaters, Sep. Purif. Technol. 60 (2008) $155-161$.

[15] P. Cañizares, F. Martínez, M.A. Rodrigo, C. Jiménez, C. Sáez, J. Lobato, Modelling of wastewater electrocoagulation processes Part II: Application to dyepolluted wastewaters and oil-in-water emulsions, Sep. Purif. Technol. 60 (2008) $147-154$.

[16] E. Lacasa, P. Cañizares, C. Sáez, F.J. Fernández, M.A. Rodrigo, Removal of arsenic by iron and aluminium electrochemically assisted Coagulation, Sep. Purif. Technol. 79 (2011) 15-19.

[17] E. Lacasa, P. Cañizares, C. Sáez, F.J. Fernández, M.A. Rodrigo, Removal of nitrates from groundwater by electrocoagulation, Chem. Eng. J. 171 (2011) 10121017.

[18] E. Lacasa, P. Cañizares, C. Sáez, F.J. Fernández, M.A. Rodrigo, Electrochemical phosphates removal using iron and aluminium electrodes, Chem. Eng. J. 172 (2011) 137- 143.

[19] J.M. Sánchez Pérez, I. Antiguedad, I. Arrate, C. García-Linares, I. Morell, The influence of nitrate leaching through unsaturated soil on groundwater pollution in an agricultural area of the Basque country: a case study, Sci. Total Environ. 317 (2003) 173-187.

[20] E. Bocanegra, D. Martínez, H. Massone, Groundwater Human Development, 2002, ISBN 987-544-063-9.

[21] APHA-AWWA-WPCF. Standard Methods for the Examination of Water and Wastewater, American Public Health Association, Washington, DC 1998. 
[22] P. Cañizares, F. Martínez, C. Jiménez, C. Sáez, M.A. Rodrigo, Technical and economic comparison of conventional and electrochemical coagulation processes, J. Chem. Technol. Biotechnol. 84 (2009) 702-710.

[23] A.E. Yilmaz, R. Boncukcuoğlu, M.M. Kocakerim, An empirical model for parameters affecting energy consumption in boron removal from boron-containing wastewaters by electrocoagulation, J. Hazard. Mater. 144 (2007) 101-107.

[24] M. Kobya, U. Gebologlu, F. Ulu, S. Oncel, E. Demirbas, Removal of arsenic from drinking water by the electrocoagulation using $\mathrm{Fe}$ and $\mathrm{Al}$ electrodes, Electrochim. Acta 56 (2011) 5060-5070.

25] S.J. Kang, K. Olmstead, K. Takacs, J. Collins, Municipal Nutrient Remova Technologies, EPA 832-R-08-006 (2008)

[26] L. Ruiping, S. Lihua, Q. Jiuhui, L. Guibai, Arsenic removal through adsorption. sand filtration and ultrafiltration: In situ precipitated ferric and manganese binary oxides as adsorbents, Desalination 249 (2009) 1233-1237 
Table 1. Values estimated for the parameters used in the mathematical model proposed for the iron electro-coagulation of water polluted with inorganic anions.

\begin{tabular}{ccc}
\hline Pollutant & $\mathbf{Q}_{\max } / \mathbf{A h ~ \mathbf { d m } ^ { - 3 }}$ & $\mathbf{K}_{\mathbf{1}} /\left(\mathbf{m g ~ d m}^{\mathbf{- 3}}\right)^{-\mathbf{1}}$ \\
\hline Arsenate & 0.15 & 10 \\
Nitrate & - & - \\
Phosphate & 0.10 & 10 \\
\hline
\end{tabular}


Table 2. Values proposed and estimated for the parameters shown in Equation 15.

\begin{tabular}{cccccc}
\hline Pollutant & $\mathbf{y}_{1}$ & $\mathbf{y 2}$ & $\mathbf{x}_{1}$ & $\mathbf{x} 2$ & $\mathbf{c}$ \\
\hline Arsenate & 0.67 & 2.01 & 5 & 12 & 0.1 \\
Nitrate & - & - & - & - & - \\
Phosphate & 0.28 & 0.83 & 5 & 12 & 0.6 \\
\hline
\end{tabular}


Table 3. Values estimated for the parameters shown in Equations 17 and 18.

\begin{tabular}{ccccc}
\hline \multirow{2}{*}{ Pollutant } & Iron electro-coagulation & \multicolumn{2}{c}{ Aluminium electro-coagulation } \\
\cline { 2 - 5 } & \multicolumn{2}{c}{$\mathrm{m}=\mathrm{a} \cdot\left(\left|\mathrm{C}_{\mathrm{n}}\right|\right)^{\mathrm{b}}$} & \multicolumn{2}{c}{$\mathrm{m}=\mathrm{a} \cdot \ln \left|\mathrm{C}_{\mathrm{n}}\right|+\mathrm{b}$} \\
\cline { 2 - 5 } & $\mathbf{a}$ & $\mathbf{b}$ & $\mathbf{a}$ & $\mathbf{b}$ \\
\hline Arsenate & 0.0088 & -0.3812 & 0.0088 & -0.3812 \\
Nitrate & 0.0005 & -0.2931 & 0.0005 & -0.2931 \\
Phosphate & 0.0004 & -0.6442 & 0.0004 & -0.6442 \\
\hline
\end{tabular}


Table 4. Raw material and energy costs estimated for the experimental conditions proposed to remove arsenates with iron or aluminium by electro-coagulation $(\mathrm{pH}: 8.5$;

$$
\left[\mathrm{AsO}_{4}{ }^{-3}-\mathrm{As}\right]_{\text {final: }} 0.01 \mathrm{mg} \mathrm{dm}^{-3} \text { ). }
$$

\begin{tabular}{|c|c|c|c|c|c|}
\hline \multirow[b]{2}{*}{$\begin{array}{c}{\left[\mathrm{AsO}_{4}{ }^{-3}-\mathrm{As}\right]_{\text {initial }} /} \\
\mathbf{m g ~ d m}^{-3}\end{array}$} & \multirow[b]{2}{*}{$\begin{array}{c}\mathbf{j} \\
/ \mathbf{m A ~} \mathbf{c m}^{-2}\end{array}$} & \multicolumn{2}{|c|}{$\begin{array}{c}\text { Iron electro-coagulation } \\
\text { costs } / \mathrm{c} € \mathrm{~m}^{-3}\end{array}$} & \multicolumn{2}{|c|}{$\begin{array}{c}\text { Aluminium electro- } \\
\text { coagulation }\end{array}$} \\
\hline & & $\begin{array}{c}\text { Raw } \\
\text { material }\end{array}$ & $\begin{array}{c}\text { Energy } \\
\text { costs }\end{array}$ & $\begin{array}{c}\text { Raw } \\
\text { material }\end{array}$ & $\begin{array}{c}\text { Energy } \\
\text { costs }\end{array}$ \\
\hline \multirow{4}{*}{1} & 0.2 & \multirow{4}{*}{0.12} & 0.01 & \multirow{4}{*}{0.54} & 0.008 \\
\hline & 0.5 & & 0.02 & & 0.01 \\
\hline & 1.0 & & 0.03 & & 0.02 \\
\hline & 4.0 & & 0.08 & & 0.06 \\
\hline \multirow{4}{*}{10} & 0.2 & \multirow{4}{*}{1.13} & 0.12 & \multirow{4}{*}{2.54} & 0.04 \\
\hline & 0.5 & & 0.20 & & 0.07 \\
\hline & 1.0 & & 0.30 & & 0.10 \\
\hline & 4.0 & & 0.76 & & 0.26 \\
\hline \multirow{4}{*}{100} & 0.2 & \multirow{4}{*}{11.28} & 1.17 & \multirow{4}{*}{22.21} & 0.34 \\
\hline & 0.5 & & 2.02 & & 0.61 \\
\hline & 1.0 & & 2.98 & & 0.91 \\
\hline & 4.0 & & 7.57 & & 2.30 \\
\hline
\end{tabular}




\section{Figure Captions}

Figure 1. Variation of parameter $m$ with the net charge $\left(C_{n}\right)$ of the system during (a) iron and (b) aluminium electro-coagulation processes for the removal of: $\bullet$ arsenates, $\Delta$ nitrates, $\square$ phosphates.

Figure 2. Experimental (solid symbols) and modelled (open symbols) removal percentage of phosphates with the electric charge applied during (a) iron and (b) aluminium electro-coagulation processes. Current densities $\left.(\mathrm{mA} \mathrm{cm})^{-2}\right)$ - 0.1 experimental, $\square 0.1$ (modelled); $\bullet 1.0$ (experimental), $\bigcirc 1.0$ (modelled); $\boldsymbol{\Delta} 3.0$ (experimental), $\Delta 3.0$ (modelled); $\$ .0$ (experimental), $\diamond 5.0$ (modelled).

Figure 3. Comparison of the removal percentage of arsenates (a), nitrates (b) or phosphates (c) obtained experimentally and by modelling for iron electro-coagulation processes. Current densities $\left(\mathrm{mA} \mathrm{cm}^{-2}\right): \mathbf{\square} 0.1 ; \Delta 0.5 ; \bullet 1.0 ; \diamond 2.0 ; \boldsymbol{\Delta} 3.0 ; \square 4.0 ; \diamond 5.0$.

Figure 4. Comparison of the removal percentage of arsenates (a), nitrates (b) or phosphates (c) obtained experimentally and by modelling for aluminium electrocoagulation processes. Current densities $\left(\mathrm{mA} \mathrm{cm}^{-2}\right): \boldsymbol{a} 0.1 ; \Delta 0.5 ; \bullet 1.0 ; \diamond 2.0 ; \boldsymbol{\Delta} 3.0 ; \square$ $4.0 ; \diamond 5.0$.

Figure 5. Influence of the current density on the coagulant dissolution rate (a) and on the voltage (b) in: $\mathbf{a l u m i n i u m}$ and $\Delta$ iron electro-coagulation processes at neutral $\mathrm{pH}$ conditions.

Figure 6. Operating costs for arsenate (a), nitrate (b) or phosphate (c) removal by iron (open symbols) and aluminium (solid symbols) electro-coagulation process. Current densities (mA cm-2): $\boldsymbol{\square} 0.2$ (aluminium), $\square 0.2$ (iron); $\Delta 4.0$ (aluminium), $\Delta 4.0$ (iron). 

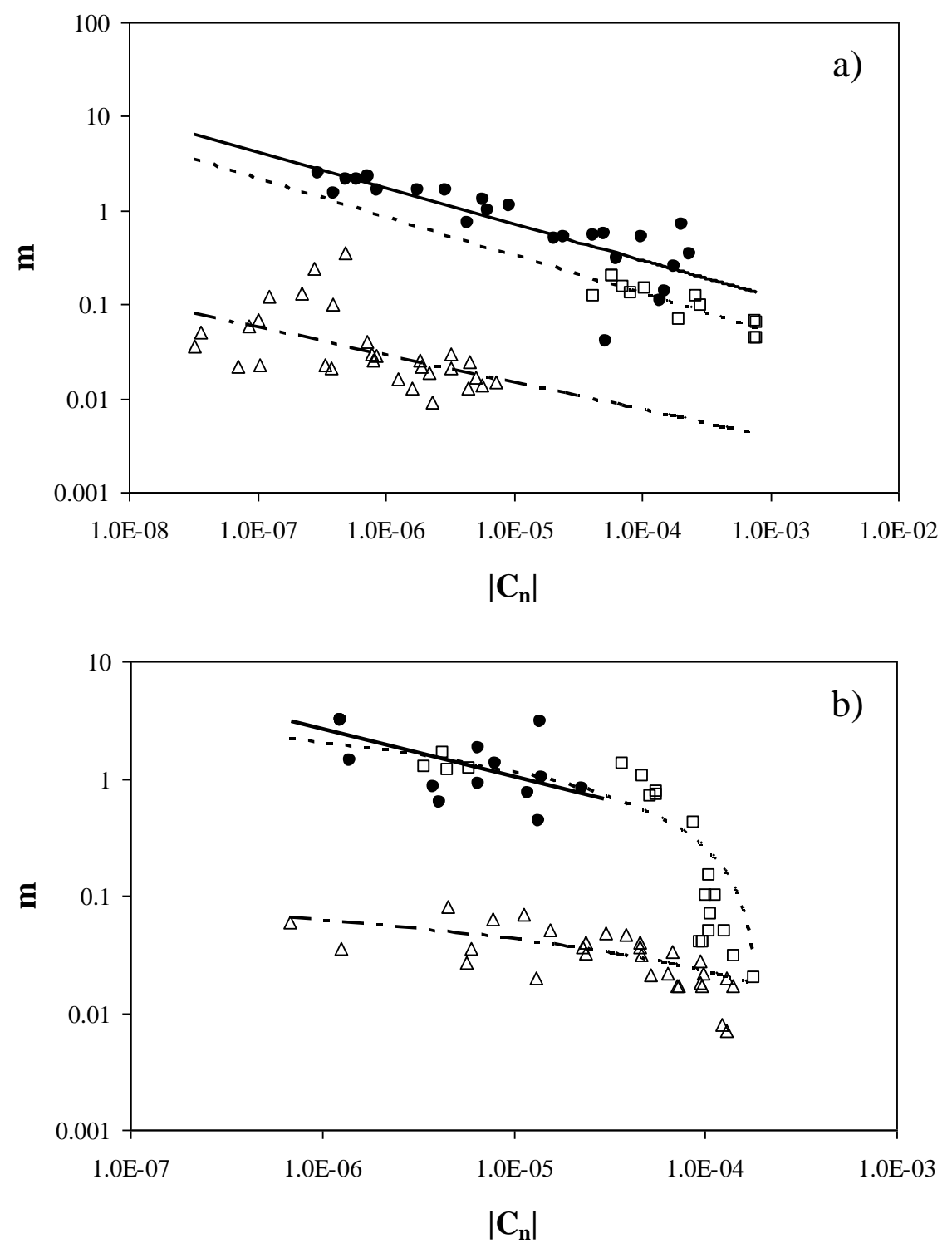

Figure 1 

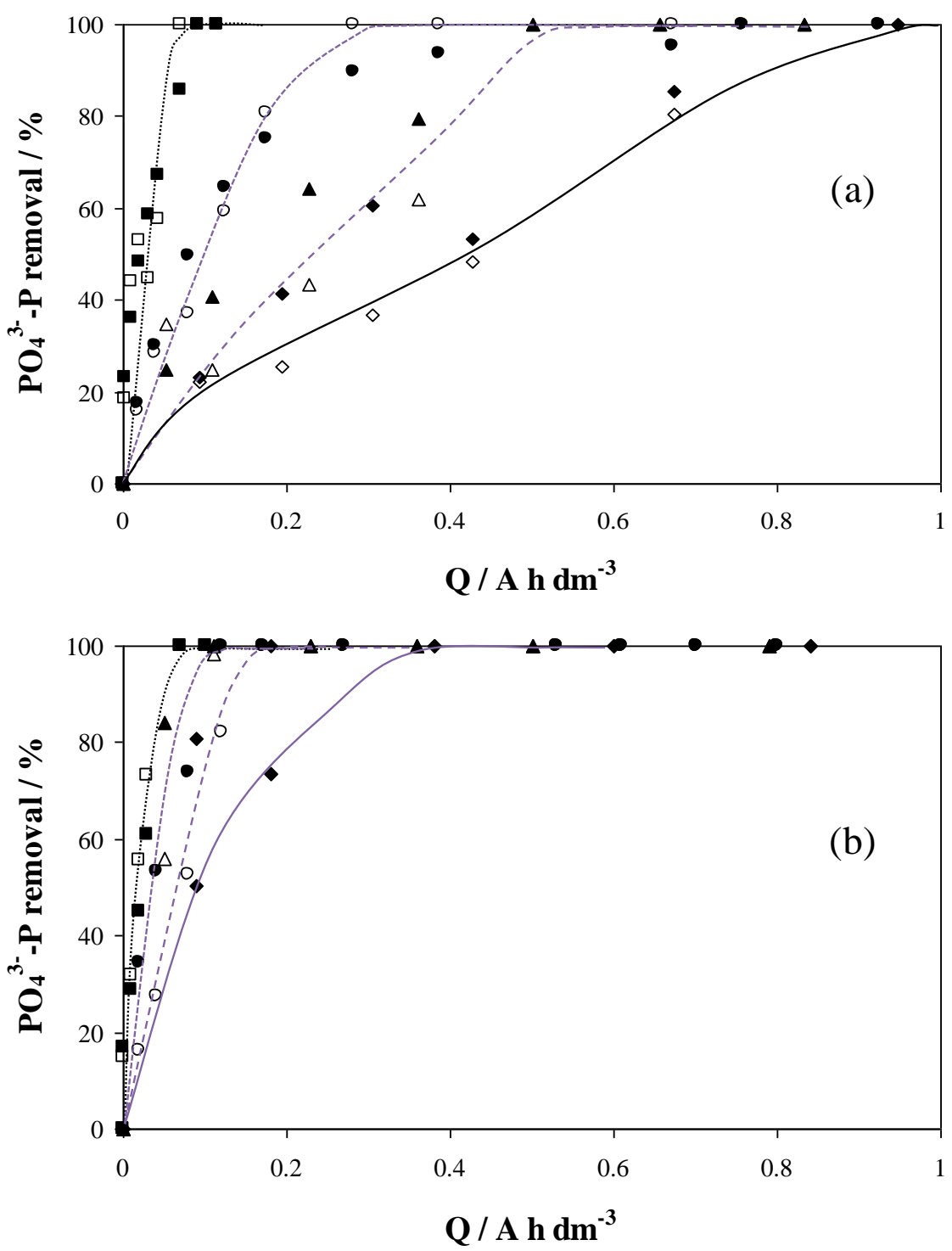

Figure 2 


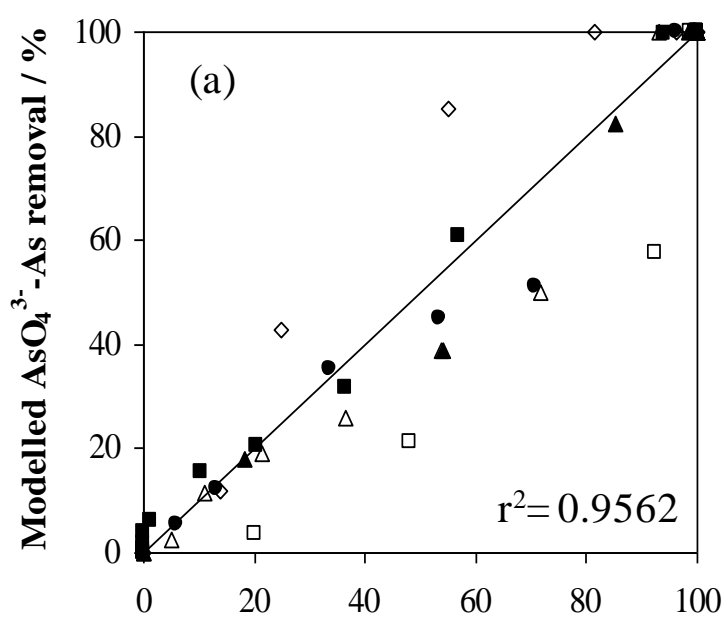

Experimental $\mathrm{AsO}_{4}{ }^{3-}$-As removal $/ \%$
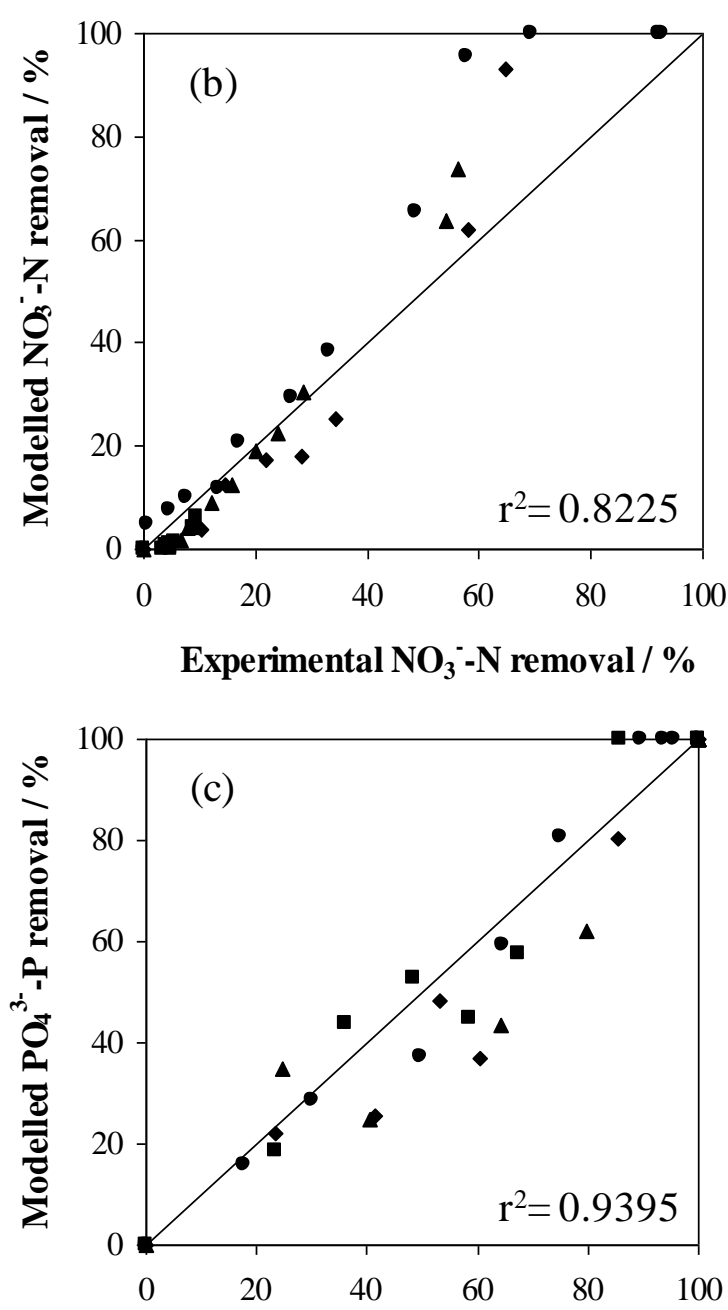

Experimental $\mathrm{PO}_{4}{ }^{3-}-\mathrm{P}$ removal $/ \%$

Figure 3 


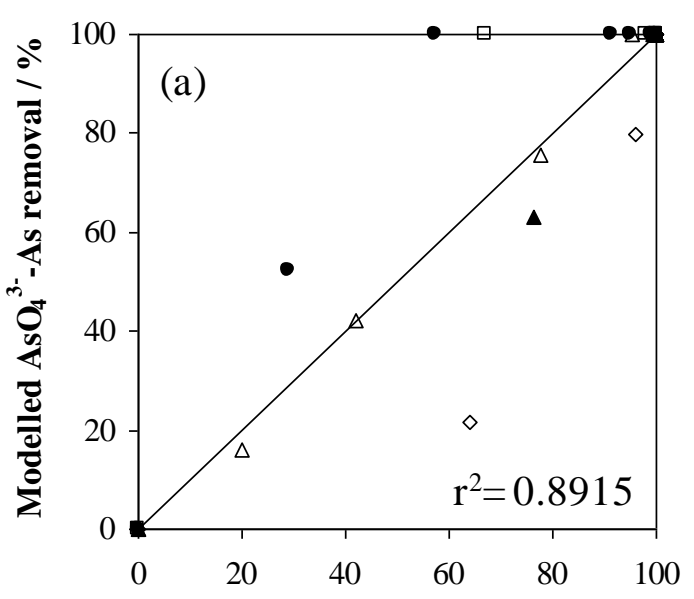

Experimental $\mathrm{AsO}_{4}{ }^{3-}$-As removal / \%

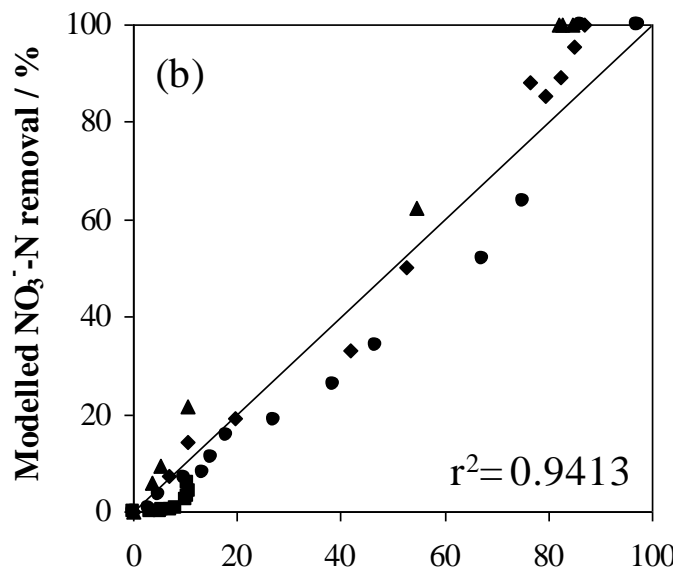

Experimental $\mathrm{NO}_{3}{ }^{-}-\mathrm{N}$ removal $/ \%$

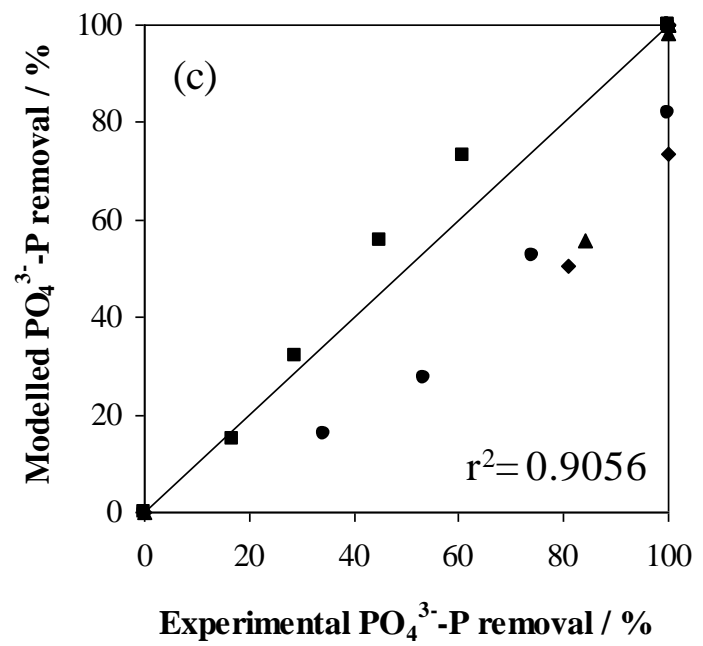

Figure 4 


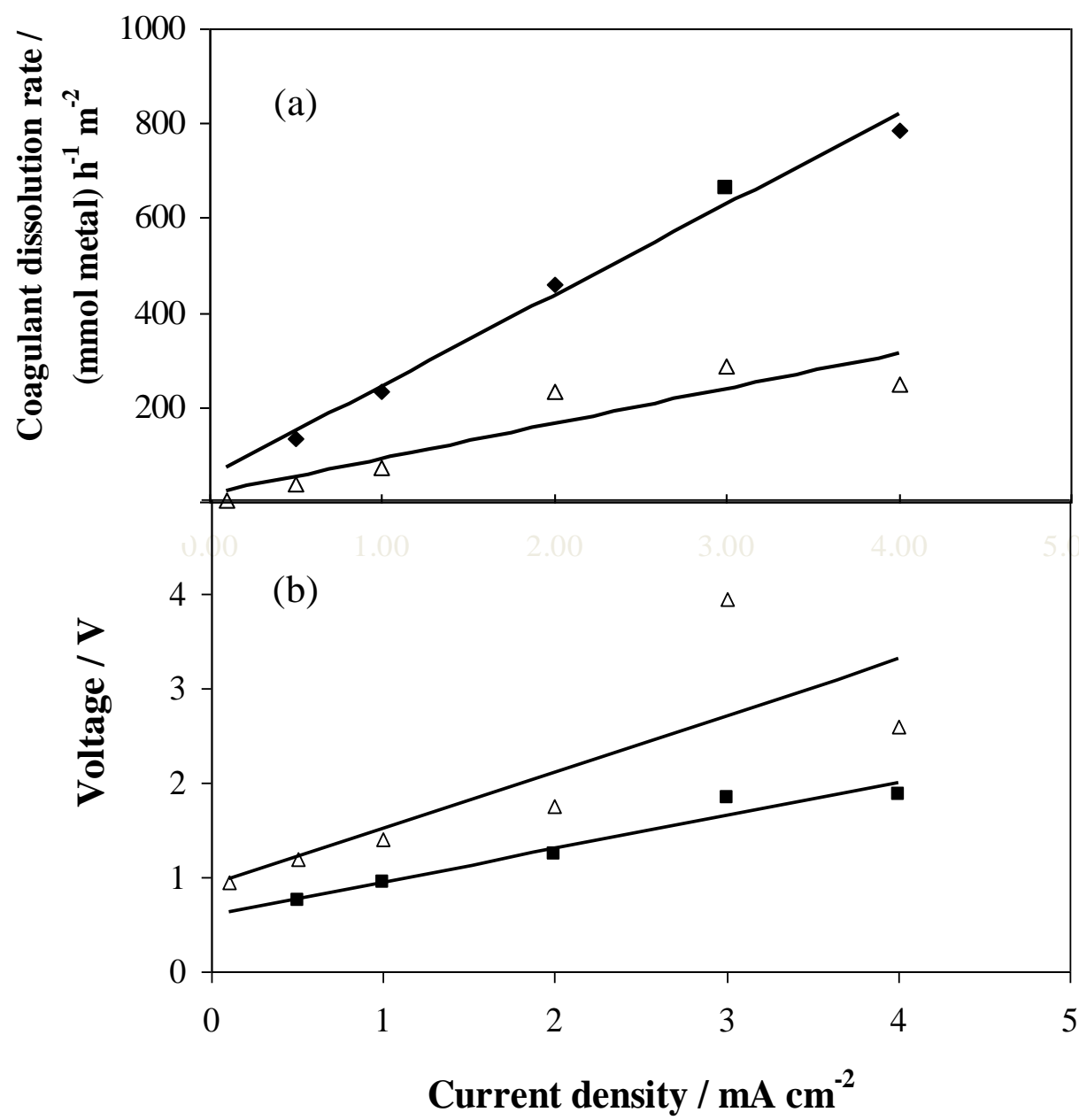

Figure 5 

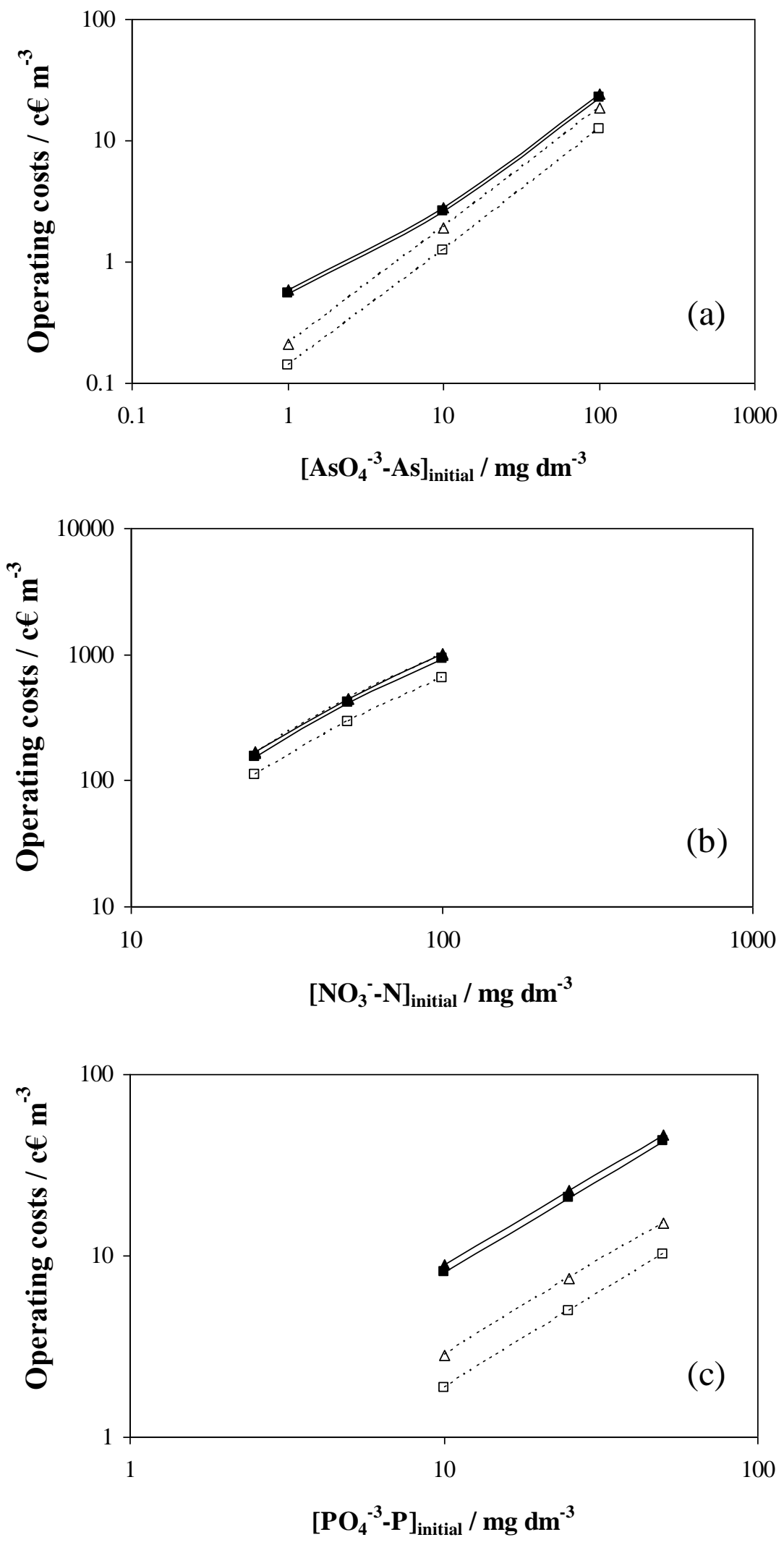

Figure 6 